\title{
PRELIMINARY RESULTS OF THE TRESPASS PREVENTION RESEARCH STUDY IN WEST PALM BEACH, FLORIDA
}

\author{
Marco daSilva \\ and Anya Carroll \\ Systems Engineering and Safety Division \\ Volpe National Transportation Systems Center \\ 55 Broadway \\ Cambridge, Massachusetts, 02142 \\ USA
}

\section{ABSTRACT}

The United States Department of Transportation's (US DOT) Research and Innovative Technology Administration's John A. Volpe National Transportation Systems Center (Volpe Center), under the direction of the US DOT Federal Railroad Administration (FRA) Office of Research and Development (R\&D), is conducting a Trespass Prevention Research Study (TPRS) in the city of West Palm Beach, Florida.

The main objective of this research is to demonstrate potential benefits, including documenting best practices and lessons learned, of implementation and evaluation of trespass prevention strategies on the rail network in West Palm Beach, Florida and all of its rights-of-way.

This technical paper will describe and provide the most up-to-date results from this study, which is beginning its second year of a three year study period. The cumulative results of the trespass prevention strategies will be analyzed to better inform the determination of areas of potential risk, develop solutions to prevent and minimize risk exposure and implement successful countermeasures in the future. Preliminary analysis from the WPB corridor trespass prevention activities are described in this technical paper. The ultimate objective of the research is to aid in the development of national recommendations or guidelines for reducing trespass-related incidents and fatalities.

\section{INTRODUCTION}

The United States Department of Transportation's (US DOT) Research and Innovative Technology Administration's John A. Volpe National Transportation Systems Center (Volpe Center) provides technical support to the US DOT Federal Railroad Administration (FRA) on all aspects of grade crossing safety and trespass research. Notable progress has been made in the past ten years in improving safety at highway-rail grade crossings. Collisions at grade crossings have declined 45 percent, and fatalities at grade crossings have declined approximately 42 percent over the past decade, between 2000 and 2009 [1]. However, although trespassrelated fatalities have also seen a general decrease over this time, the rate has not been as good as the success experienced at grade crossings. Additionally, trespass fatalities surpassed the number of fatalities at grade crossings in 1997. Although trespass fatalities have declined by about 8 percent over the past decade to 428 in 2009, much work still needs to be done in the area.

The FRA has been interested in trespass mitigation for many years, and especially since 1997 when trespass fatalities exceeded grade-crossing fatalities. One of the latest efforts was a collaborative effort between the USDOT/FRA Office of Railroad Safety, the Federal Transit Administration (FTA) and Caltrain, which resulted in a very successful workshop in 2008 at Caltrain headquarters in San Carlos, California, dealing with Right-of-Way (ROW) fatalities and trespass [2]. The 
workshop, designed to bring together major stakeholders affected by this issue and whose goal was to share best practices in dealing with it, was deemed extremely successful. A second workshop is currently being planned for 2011.

The Rail Safety Improvement Act (RSIA) of 2008 [3] was also enacted along this same time period. Section 208 of the RSIA specifically addresses trespasser prevention and highway-rail grade crossing safety. Part of Section 208 states:

"In consultation with affected parties, the Secretary of Transportation shall evaluate and review current local, State, and Federal laws regarding trespassing on railroad property, vandalism affecting railroad safety, and violations of highway-rail grade crossing signs, signals, markings, or other warning devices and develop model prevention strategies and enforcement laws to be used for the consideration of State and local legislatures and governmental entities.” [3,H.R. 2095-28]

As a result of the 2008 workshop, the Rail Safety Improvement Act of 2008, and direction from the FRA Office of Railroad Safety, the FRA Office of Research and Development (R\&D) funded a study on trespass prevention strategies with the ultimate goal of developing and demonstrating trespass prevention and mitigation best practices that could form the basis for national guidelines on the topic. Specifically, the Volpe Center was tasked by the FRA Office of R\&D to conduct a Trespass Prevention Research Study (TPRS) on a roughly 7-mile stretch of South Florida Regional Transportation Authority (SFRTA) Right-ofWay (ROW) and 5-mile Florida East Coat Railway Company (FEC) ROW in the city of West Palm Beach, Florida.

\section{BACKGROUND}

The SFRTA's TriRail service, which is a commuter rail operation between Miami and West Palm Beach, was originally selected for this research study that began in July 2009. SFRTA experienced a record number of casualties in 2008 with regard to trespass events in Palm Beach County, as shown in Figure 1 [1]. It should be noted that it was operated as the Tri-County Commuter Rail Authority (TCCX) before 2008. A $1 \frac{1}{2}$ to $1 \frac{3}{4}$ mile stretch of ROW from 45th Street and Okeechobee Boulevard in the city of West Palm Beach, FL, was the focus of four of the 5 fatalities in the county in 2008.

Previous to the TPRS, SFRTA reached out to the state and local community in West Palm Beach. These included the Florida DOT, Florida Operation Lifesaver, Palm Beach County and West Palm Beach authorities, and local organizations. This formalized group started the dialogue necessary for development of a community strategy to mitigate the trespass problem in the area. One of the initial goals of the TPRS research activity was to re-energize and build upon this already established group.
The original scope of the TPRS was only in relation to trespass concerns along the SFRTA operations within West Palm Beach, Florida. Upon initial review of incident data and site visits, the scope was later expanded to all rail lines in the West Palm Beach, Florida area to include the FEC, which owns and operates a freight-only line on a separate ROW to the East of the SFRTA line within West Palm Beach. As shown in Figure 1, FEC also has a major problem with trespassing on its ROW within the study area. In fact, there were more trespass casualties reported by FEC than by all other operations combined, except for 2008 where SFRTA experienced the most. A map of the two rail lines within the study area is shown in Figure 2. It should be noted that the SFRTA line is all double-tracked and equipped with fourquadrant and pedestrian gates at all crossings in the study area. Additionally, the ROW is owned by Florida DOT and operated by CSX, which runs freight trains on the line. Amtrak also runs passenger service over the same line. FEC uses its line, composed of both single-track and double-track segments throughout the study area, for freight operations.

\section{RESEARCH METHODOLOGY}

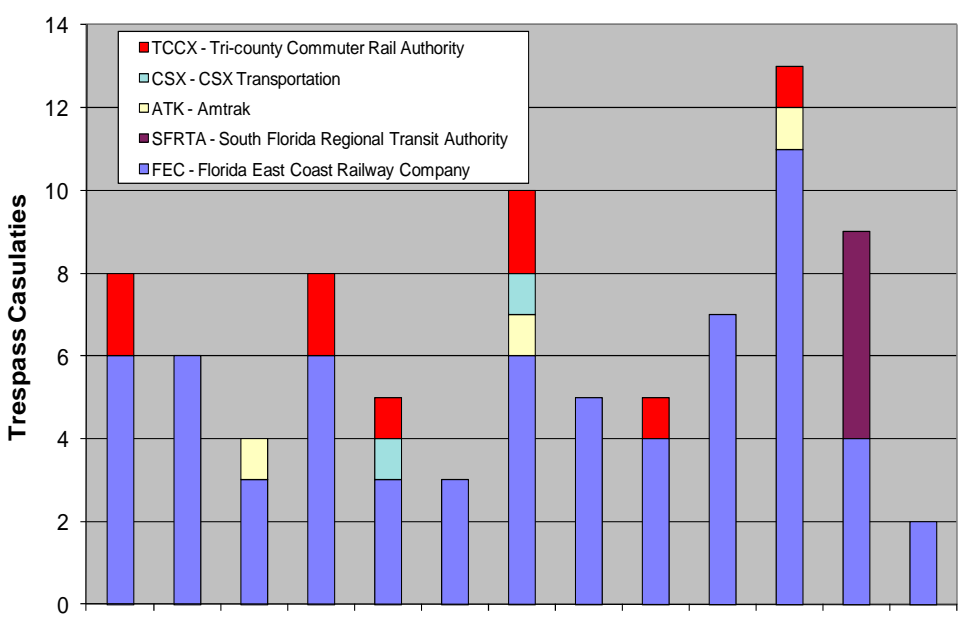

Figure 1. Trespass Incidents in Palm Beach County, 1997-2009 Year

A Community, Analysis, Response and Evaluation (CARE) guide was developed by Transport Canada to create safer communities by fostering the development of long-term trespass prevention strategies through collaborative community problem-solving partnerships to reduce trespass fatalities [4]. Although used in Canada for dealing with ROW trespass issues at the local level, the procedures and benefits of this guide have yet to be fully evaluated in the US. The TPRS research team used the CARE guide as a baseline for developing a plan to mitigate the trespass issue in West Palm Beach. 


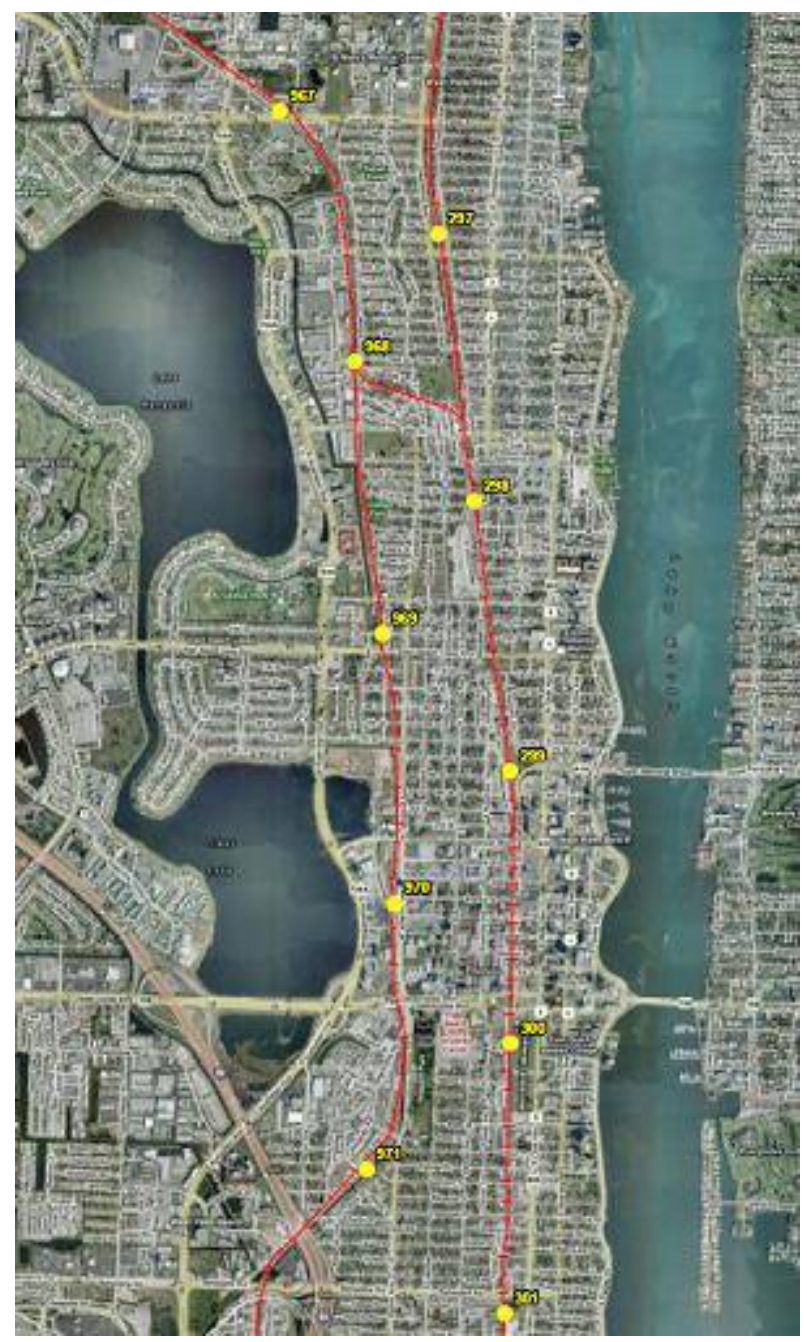

Figure 2. West Palm Beach Study Area (SFRTA TriRail line on left, FEC line on right)

The CARE guidance is a collaborative problem-solving approach to addressing trespass on railroad lines in communities. The goal of CARE is to create safer communities by fostering the development of long-term trespass prevention strategies through collaborative community problem-solving partnerships [4]. This process consists of four steps:

1. COMMUNITY: Identification of the trespassing problem within the community, and the associated stakeholders

2. ANALYSIS: Data analysis of the trespassing problem and determine the underpinning causes

3. RESPONSE: Identification and implementation of the most effective response(s)

4. EVALUATION: Evaluation of the effectiveness of the treatment implemented. [4]
The Volpe Center research team used this outline to initiate its three-year research project, which started in July 2009. The methodology is centered on working with the SFRTA stakeholder partnership to review the CARE guide and adjust as necessary, and demonstrate potential benefits, including documenting best practices and lessons learned, of implementation and evaluation of trespass prevention strategies on the rail network in West Palm Beach, Florida and all of its rights-of-way. To date, step 1 has been completed and step 2 is in progress. The other two steps have yet to be initiated in this three year project.

\section{SFRTA STAKEHOLDER PARTNERSHIP}

As already discussed, the identification of stakeholders, which is the first step in the CARE guidance, and formation of a stakeholder group had already been initiated before the research study. The first action of the Volpe Center research team was to convene the original group, discuss the research project, and build up momentum for the effort. The team also identified and invited additional stakeholders into the group, formerly known as the Stakeholders Users Group (SUG). The SUG is currently comprised of representatives from the following entities:

- $\quad$ FRA

o Office of Railroad Safety

o Office of Research and Development

- $\quad$ Volpe Center

- SFRTA

o Safety and Security

o Veolia (contract operator)

o Wackenhut (contract security)

- FEC

- Amtrak

- CSX

- FL DOT

- West Palm Beach

o Mayor's Office

o Police Department

o Engineering Services Department

o Planning and Zoning Department

o Neighborhood Associations

- Palm Beach County

o Sheriff's Office

o School District

- FL Operation Lifesaver

- Transport Canada

To date, a total of five SUG meetings have been held: October 2009, February 2010, April 2010, July 2010, and October 2010. These quarterly meetings, facilitated by Volpe Center staff, are designed to provide an update to the SUG 
members on the status of the project, share any new information and analysis results, and develop new action items as well as address any outstanding action items.

In addition to holding quarterly meetings with the SUG, the research team has also performed several site visits and developed a listing of trouble-spot locations both on the SFRTA and FEC railroad lines.

\section{DATA ANALYSIS}

The second step in the research process is to analyze the data and try to determine the underpinning causes of the trespass problem. Specific to the TPRS, the research team identified several sources of trespass data. These are:

- FRA incident data

- Local law enforcement violation data

- $\quad$ Operating Railroad trespass data

o Incidents

o Train crew observations

o Locomotive video

- $\quad$ Field observations by research team

The FRA incident data related to trespass, although very important, does not currently provide enough information as to exact location of trespass incidents to yield any accurate determination of trespass location. Currently, this data is only reported at the county level, as shown in Figure 1. Additionally, since trespass casualties are relatively rare (SFRTA experienced 4 fatal casualties in 2008 along the study area), surrogate measures of safety need to be considered for analysis. Examples of surrogate measures include violation data reported by local law enforcement, locomotive crew observations, and video recording of specific locations. Although the research staff has requested and received some law enforcement and locomotive crew observation data, the bulk of the analysis to date has focused on locomotive video data supplied by SFRTA.

\section{Preliminary Analysis of SFRTA Locomotive Video Data}

SFRTA provided the Volpe Center research team with a locomotive video data from a sample of their trips through the study area in the city of West Palm Beach. The study area consists of roughly 7 route miles along the ROW, which the trains take an average of about 15 minutes to traverse. The current data set contains video data from 613 trips dating from March 5, 2010 to July 5, 2010. This 4-month data set represents roughly 10 percent of all SFRTA trips through the city of West Palm Beach during that period. The main objective of analysis of this video was to determine which locations along the study area were more prone to trespassing and provide trespass rate data for existing conditions. This data could then be used to evaluate the effectiveness of implemented treatments. It should be noted that there are several limitations with the video analyzed in this study, some of which may have a significant impact on the use of this data. The more significant issue is that the video data is grainy at times and potential trespassers may not be detected by visual analysis of the video. Taking this into account, the data is able to still present a very detailed and comprehensive picture of the trespass issue.

A trespass event was defined as an event involving a person or cyclist on the railroad ROW identified via analysis of the video data. Trespass events were further classified into two sub-types: at grade crossings, and on the ROW. Trespassing at a grade-crossing was defined as a person occupying the crossing while the grade crossing gates were in the down position, which follows the same definition of a trespasser at a gated crossing as defined by the FRA [5]. As already mentioned, the SFRTA line in the study area is doubletracked and all crossings are equipped with four-quadrant and pedestrian gates. An example of this type of event in shown in Figure 3, which shows a pedestrian and a cyclist violating the down gates at the Banyan Boulevard crossing after the train has passed (this view is from the rear cab-car). The other trespass type, trespassing on the ROW, was used to capture all non-grade crossing trespassing. An example of this type of event is shown in Figure 4, which shows two trespassers on the ROW.

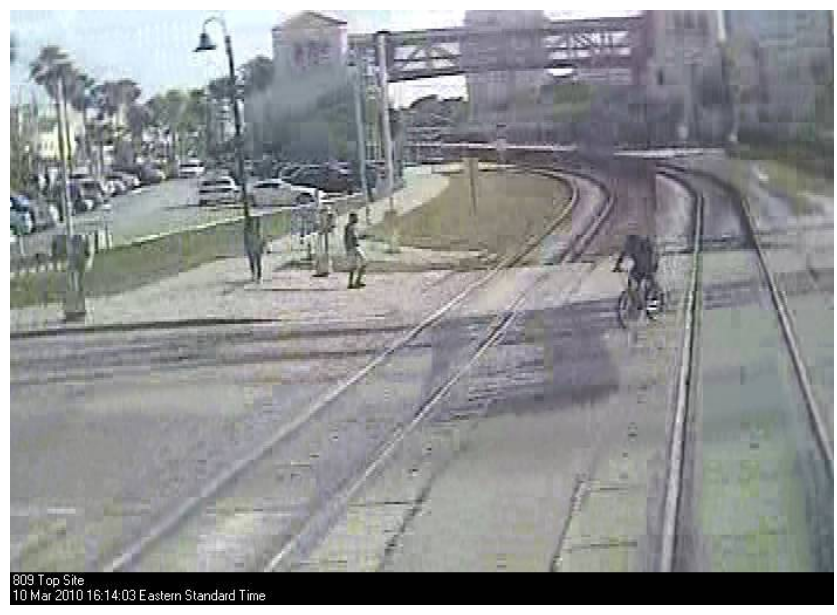

Figure 3. Grade Crossing Trespass Event

A total of 176 trespass events involving 230 trespassers were identified through the review of the set of 613 trips. This averaged out to about 0.3 trespass events per trip, or 1 trespass event every 3.5 trips. A total of 60 of the 176 events involved trespassing at a crossing either before or after a train while the gates were in the down position. The remaining 116 events involved trespassers along the ROW at non-crossing locations. Figure 5 shows the distribution of each type of trespass event. 


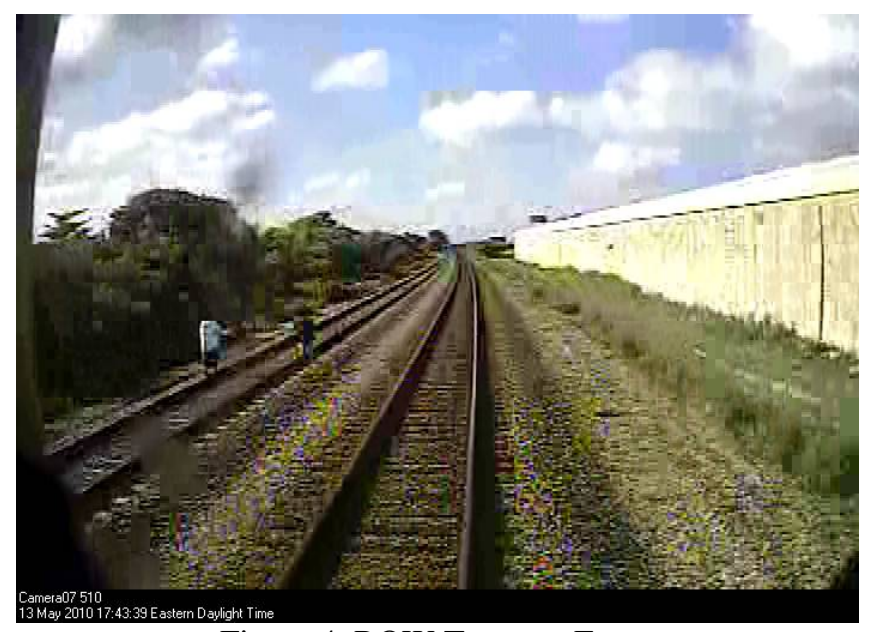

Figure 4. ROW Trespass Event

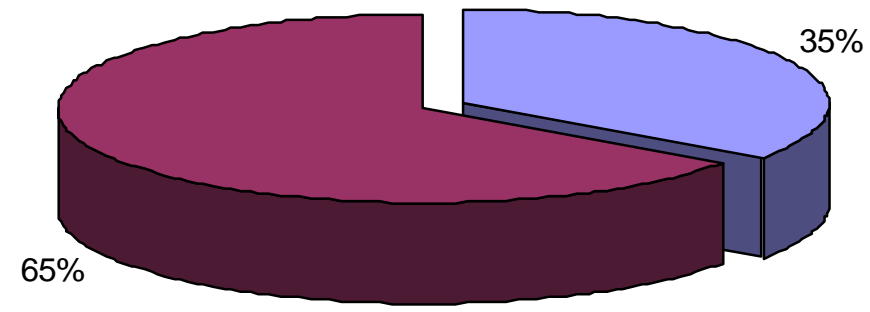

Grade Crossing Trespass $\square$ ROW Trespass

Figure 5. Trespass Event Location, SFRTA Locomotive Video Data

As shown in Table 1, most of the grade crossing trespass events involved pedestrians or cyclists violating the gates after the train. As already mentioned, the SFRTA line is doubletrack throughout the study area. A significant risk of a second train approaching from the opposite direction while the gates are still down exists. In fact, 7 percent of the cases were classified as second train events, where the trespasser violated the crossing gates after one train has passed and while a second train was approaching. About 12 percent of the 60 grade crossing trespass events identified in the locomotive video data occurred before the train (during its approach to the crossing). The last type of event, identified as "Neither", involved trespassers waiting past the downed gates for the train to clear the crossing.
Table 1. Grade Crossing Trespass Event Types

\begin{tabular}{|l|c|c|}
\hline \multicolumn{1}{|c|}{ Type } & Count & Frequency \\
\hline After Train & 46 & $77 \%$ \\
\hline Before Train & 7 & $12 \%$ \\
\hline Second Train & 4 & $7 \%$ \\
\hline Neither & 3 & $5 \%$ \\
\hline \hline \multicolumn{1}{|c|}{ Total } & $\mathbf{6 0}$ & $\mathbf{1 0 0 \%}$ \\
\hline
\end{tabular}

Figure 6 shows the breakdown of trespass events by time of day. Overall, about 70 percent of the trespass events occurred after 12PM. The data also reveals that the highest number of trespass events on the SFRTA line within the study area occurred during the 3PM to 6PM time period, regardless of event type. It should be noted, that of the 50 weekday trips by the SFRTA line, at total of 22 trips pass through the study area in the morning hours and 28 in the afternoon and evening hours. Additional data analysis will focus on normalizing this data per train frequency.

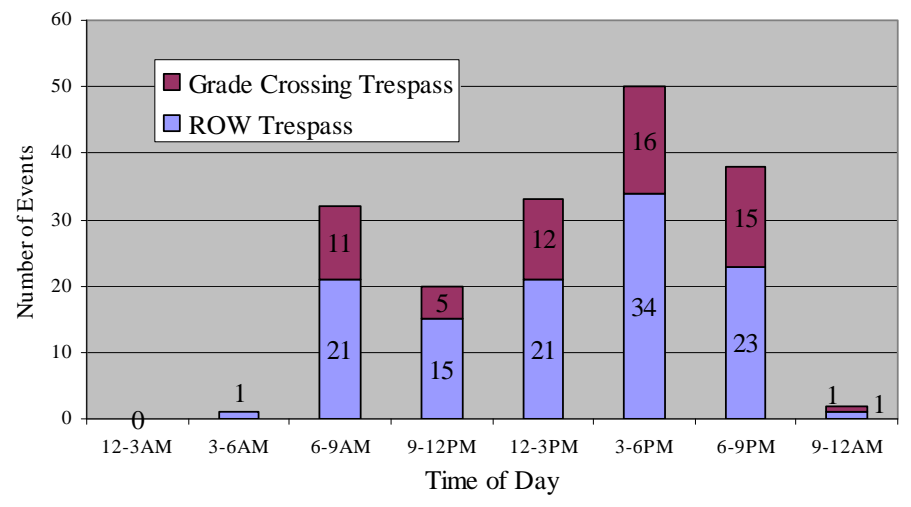

Figure 6. Trespass Events by Time of Day

The main objective of the analysis of the SFRTA locomotive video data was to help identify and quantify the trespass problem. All of the trespass data were plotted on a geobrowser to visually depict trespass events along the SFRTA study area.

Figure 7 shows the locations of all 176 trespass events. The numbers on the graphic identify each event as listed in the data base created by the Volpe Center research team. Although it can be easily seen that the trespass problem is present almost everywhere along the line, it is difficult to determine specific trouble spots at this level of detail. Figure 8 displays the zoomed-in area identified by the red circle within Figure 7, which covers the south approach to the West Palm Beach station. A total of 13 out of the $116 \mathrm{ROW}$ trespass events were recorded at that location alone. Additionally, 12 of the 13 events at this location involved a trespasser crossing over the track, which amounts to almost 40 
percent of the 31 ROW events involving trespassers crossing the tracks at non-grade crossing locations in the study area.

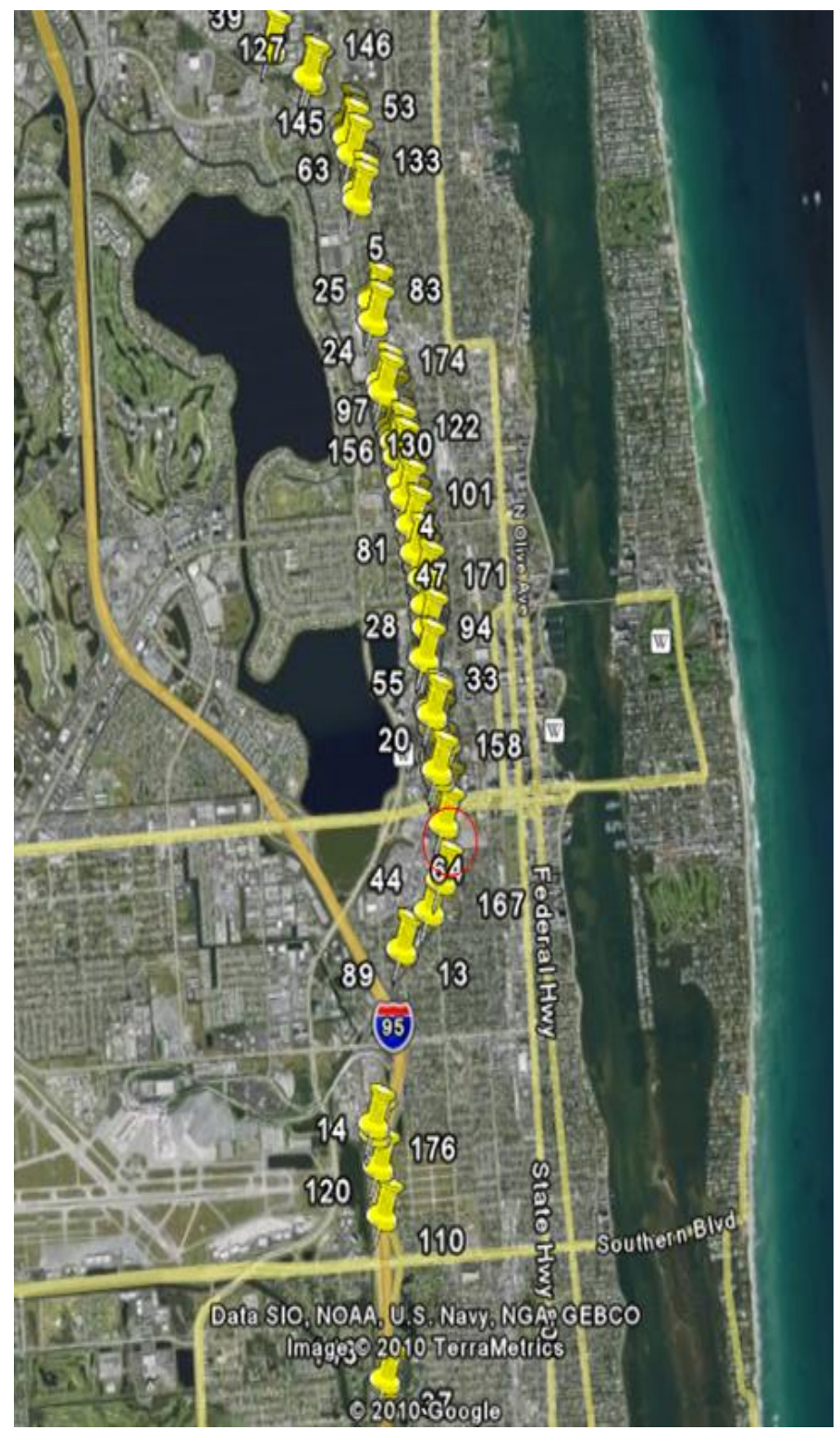

Figure 7. Location of Trespass Events on SFRTA Line

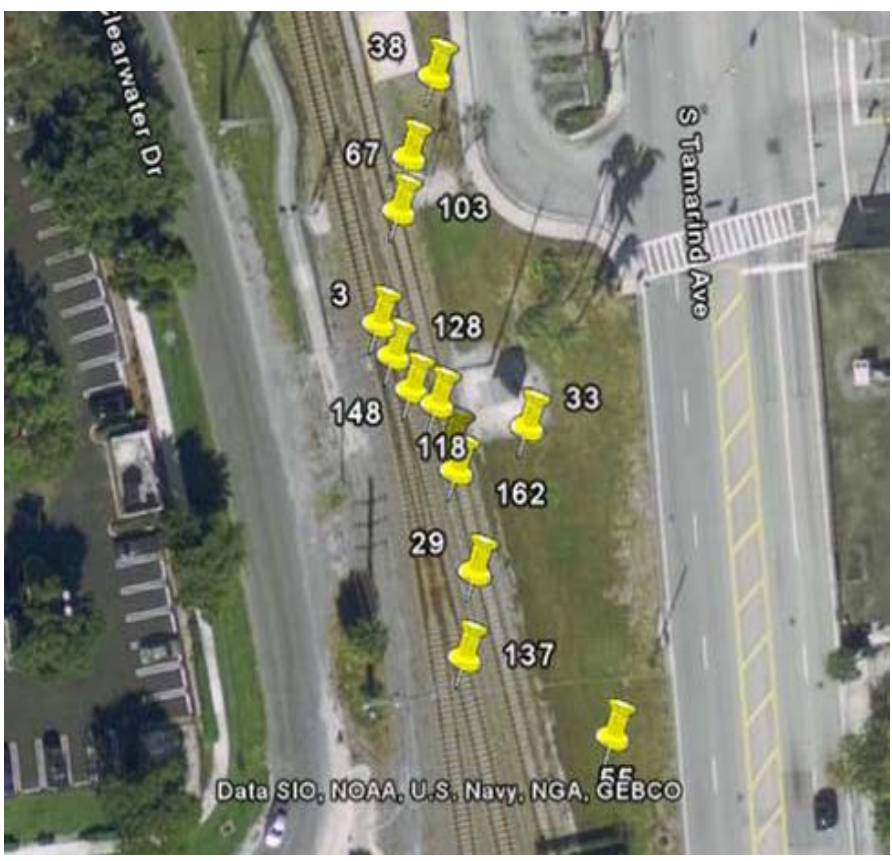

Figure 8. Trespass Event Locations on South Approach to West Palm Beach Station

\section{Preliminary Analysis of FEC data}

Unlike SFRTA, no locomotive video data was available from FEC. However, the research team performed multiple site visits to known trouble spots all along the ROW within the study area and catalogued a total of 32 locations where there was evidence of trespass (observed trespassing, worn paths, and breaks in fencing). Additionally, data from the Palm Beach County School District Police, which has yet to be analyzed, will provide more information as to where and why there is a significant trespass issue particularly towards the north end of the city. The research team observed many instances in that general area involving children with backpacks trespassing across the FEC tracks. Figure 9 shows an example of such an event observed by the research team during a site visit in April 2010. During that same visit at that same location, the research team observed fifteen trespassers in less than 30 minutes. Most of the trespassers were children or teenagers crossing over the tracks. The research team engaged in discussions with the Palm Beach County School District to ascertain the underlying cause of this issue, which may have to do with the catchment area of the local schools (the geographic area from which students are eligible to attend a local school) and substantial distance between grade crossings in that area. 


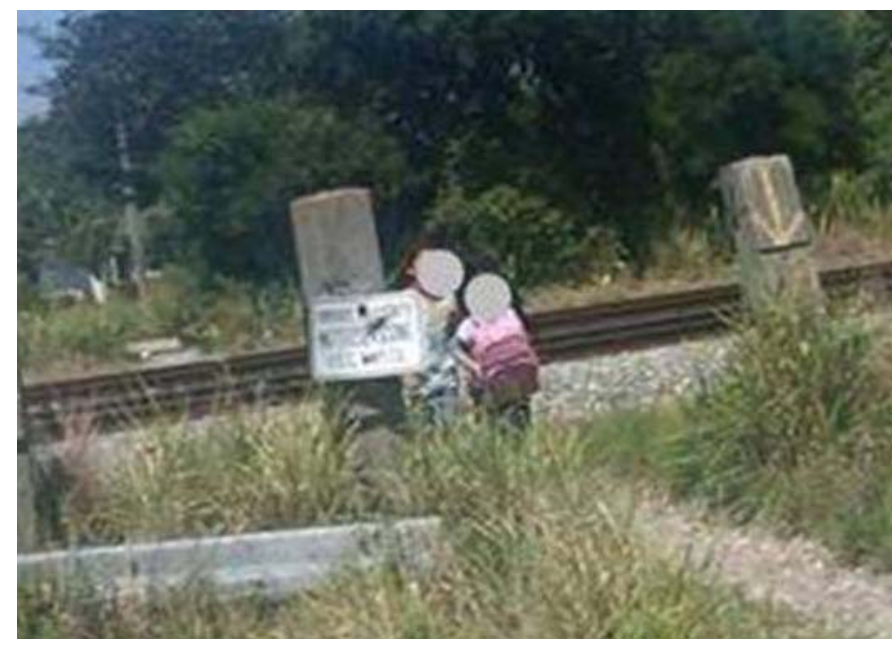

Figure 9. FEC ROW Trespass Event Example

\section{NEXT STEPS}

As outlined in this paper, the TPRS project team has completed the first step in the collaborative effort to address the trespass problem in the West Palm Beach community, which involved identifying and involving all potential community stakeholders. The data analysis step, which is the second step in this process, is currently in progress. Once this step is completed, the research team will move to propose a set of feasible responses to mitigate the trespass problem. These responses will most likely consist of engineering (such as fences, signs, or other anti-trespass technologies, or possibly new crossings), education (such as signs, posters, public service announcements, Operation Lifesaver), and enforcement (which may also include legislative efforts). Some of these recommendations may be system-wide recommendations while others may be aimed to specific locations or segments of the population.

It is the hope of the research team that the stakeholders implement one or more recommendations from this study, which the research team will then evaluate. Finally, a set of national recommendations or guidelines will be developed based on the process validated through this study. These recommendations could then be used to develop model prevention strategies as called for in the recently enacted Rail Safety Improvement Act of 2008.

\section{ACKNOWLEDGEMENTS}

The authors would like to thank Sam Alibrahim, Chief of the Signals, Train Control and Communications Division, FRA, and Leonard Allen, Program Manager, Signals, Train Control and Communications Division, FRA for their guidance and direction during the project. The authors would like to acknowledge Daniel Knote, Chief of the Passenger Rail
Safety Division, FRA, for his technical and organizational leadership. The authors would also like to acknowledge Tashi Ngamdung, Patrick, Bien-Aime, Bernard Kennedy, and Roxanne Tully, all of the Systems Engineering and Safety Division, Volpe Center, for their support in data collection and analysis. Additionally, special thanks to all of the members of the TPRS Stakeholders Users Group.

\section{REFERENCES}

[1] http://safetydata.fra.dot.gov/OfficeofSafety/default.aspx, last accessed November, 2010.

[2] Adduci, et al, ROW Fatality and Trespass Reduction Workshop 2008 - Summary of Results, Washington, DC; U.S. DOT, February 2009.

[3] Rail Safety Improvement Act of 2008 (Public Law 110432, 122 Stat. 4848-4970)

[4] Direction 2006. Trespassing on Railway lines, A Community Problem-Solving Guide. www.direction2006.com/documents/pdf/en_TrespGuide2 003.pdf, last accessed December 7, 2010.

[5] FRA (1997). FRA Guide for Preparing Accidents/Incidents Reports. Report No. DOT/FRA/RRS22. 